\title{
The Linguistics of Social Networking: A Study of Writing Conventions on Facebook
}

\author{
Carmen Pérez-Sabater (València)
}

\begin{abstract}
Scholarly research on computer-mediated communication discourse has mainly centred upon the linguistic characteristics of emails, focusing on the formal and informal features and the orality involved in this form of communication. This paper presents a new insight into the study of computer-mediated communication (CMC) by analysing a fairly recent genre of computer-mediated communication, comments posted on the new social networking websites. The research undertaken examines the comments published on the official Facebook sites of some universities to observe the level of formality/informality of online communication in English. The distinction between online writings by native and non-native speakers of English has been considered as well. The study focuses on the formulae of etiquette and protocol used for salutation, opening, pre-closing and closing as an indicator of the degree of orality and informality in online writing. Data reveal that, in the specific context of the university, the use of Facebook is not conventionalised, as the comments posted on Facebook present important stylistic variations. Moreover, in most instances non-native speakers of English display more formal traits than native speakers when communicating electronically on social networking sites in the academic world.
\end{abstract}

\section{$1 \quad$ Introduction}

In the last few years, information and communication technologies have evolved rapidly and have created new forms of literacies. As a result, new online genres have emerged in academic genres and discourses (cf. Kuteeva 2011). The incorporation of the new electronic genres to the academic world has affected the use of established traditional communication exchange media in university organisations. Computer-mediated interaction in the academic world has changed the way we write and the genres we create (cf. Hyland/Hamp-Lyons 2002). Focusing on this specific context, the development of social networking and its increasing importance in the academic world creates the need for scholarly research on the issue. The research undertaken examines the use of the English language in the comments posted on the social networking website Facebook, the most popular social networking website at the moment (cf. Facebook Inc. 2012). As will be detailed below, Facebook is used as a research context in order to determine whether a specific tool of this networking application, that of posting comments, is a conventionalised genre of computer-mediated communication, despite its relative novelty.

\subsection{Computer-mediated communication (CMC) and the academic world}

For the last twenty years, the branch of linguistics dedicated to computer-mediated communication (CMC) has centred on many perspectives, focusing mainly on the characteristics of emails (see, for example, Baron 2000; Yates 2000). 
Regarding the language used in emails, although written, its style has been characterised as written speech (Maynor 1994), or "as an emerging language centaur-part speech, part writing" (Baron 2000: 248). The oral and highly informal traits of email have been pointed out by Yates/Orlikowski (1992) in contrast with the language used in traditional memos (see Cho 2010 for a recent reformulation of this perspective). In relation to these oral traits, the dialogic nature of emails has been underlined. This characteristic of email messages could be extended to other CMC genres (cf. Pérez-Sabater 2011). The dialogic nature of online genres has a close relationship with the concept used by Bakhtin (1986) in his literary theory, where the dialogic character of literature is emphasised as being in communication with other previous or future works, and the dialogic character of language is also postulated as being in response to what has been said or is going to be said. Language is relational and engaged in a process, as are these online writings; they are, in most cases, in response to other previous communications, and are linked to future ones.

In the field of English for Academic or Special Purposes, some stylistic protocols have been developed so as to use this means of communication proficiently with an adequate level of formality in business, academic or personal emails, (see for example Emmerson 2004). Emails were originally designed for academic-organisational purposes (cf. Yates 2000). In academic settings, email messages are the most popular genre of computer-mediated communication used by administrators and academics. In the survey carried out by Zimmerman/Bar-Ilan (2009), 96.9\% of academics use it regularly. On the contrary, email doesn't seem to suit the communicative needs of university students who consider it too formal, and only adequate for communicating with teachers (cf. Yus 2011).

As for the linguistics of this online genre, participants' use of the language is usually more formal than in synchronous discussion, since authors have more time to plan their writing and, thus, pay more attention to form. Nevertheless, depending on the topic discussed, the formal character of online fora can vary; this linguistic variation is perceived in the discussion of fora dedicated to entertainment topics, such as profanity (cf. Herring 2001), or in football fora, compared to fora devoted to serious political topics (cf. Montero-Fleta et al. 2009). In the university, online fora are available in many situations where student interaction is enhanced, for example, in some subjects or some organisations within the university, like students' unions.

\subsection{The social networking site Facebook}

The growth of Web 2.0 has allowed many services to be created that facilitate collaboration in the World Wide Web. They are defined as "web-based services that allow individuals to construct a public or semi-public profile ... articulate a list of other users with whom they share a connection and view and traverse their list of connections" (Boyd/Ellison 2008: 211). The affordances and reach of this emergent phenomenon are increasingly attracting the attention of scholars to the study of social networking (cf. Boyd/Ellison 2008).

In the last few years, some social networking sites have disappeared and some others are gaining users day by day. One of the top social networking websites at the moment is Facebook. Created in 2004 "as a cross between a tool for meeting new people and a platform for networking with people you already know" (Baron 2008: 84), Facebook has its origins in the University of Harvard (cf. Boyd/Ellison 2008). This website, privately owned by Facebook, Inc., was quickly transformed from a private club within the University of Harvard to a service open to everyone in 2006. On this social site, users create an online profile by listing personal information and interests, link up with other users and share updates of the information posted on a daily basis (cf. Hargittai/Hsieh 2011). Participants may use this network application to interact with people they already know or to meet new people that are 
The linguistics of social networking: A study of writing conventions on Facebook

called friends, that is, participants "who can post comments on each other's pages, and view each other's profiles" (Ellison et al. 2007).

The website includes several features, such as communication through private or public messages, a chat, online fora, photos, videos, links, a personal Wall, and News Feed, where friends or participants can post their messages and comment on topics. The company is constantly modifying and improving the services provided, offering more and more online services.

The most interesting characteristic of this site is that it enables a great variety of online genres to be accessed through the same platform; these genres being both synchronous and asynchronous. They are easily identified and can be organised and customised in the way the user of the site desires, some services can be visible to the whole online community and some cannot. Battner/Fiori (2009) put forward that it is a tool that goes beyond synchronous and asynchronous technologies; as part of Web 2.0 principles, it is a participatory platform where users can add information or modify the information already online, for example, a user can tag the pictures uploaded by adding the names of the people or a description. Any user can create a group and this can be open to other users, or restricted to a pre-selected community (cf. Battner/Fiori 2009). It is also interesting to point out that the original platform designed to keep in touch effectively with former classmates has evolved into a more diversified online tool. Now, Facebook is used as a platform for online communities that share interests in many fields: these being political, sportive, educational, scientific, commercial, or entertainment, among others. The typical user spends more than 20 minutes daily and logs on at least once a day (cf. Ellison et al. 2007).

As for the research carried out on Facebook, most scholars have analysed the use of Facebook from a sociological or pragmatic approach identifying the sense of community in the relationship between participants in social networking (cf. Ellison et al. 2007; Baron 2008; Papacharissi 2011; Yus 2011). It has also been studied as a platform to enhance learning (see for example, Blattner/Fiori 2009). In contrast, little is known about the linguistics of this online social networking website. Literature on the study of the linguistic aspects of the social networking website Facebook is very scarce; the reason for this may not only be because of its novelty but also because of the fact that it is very complex to study, as several genres are concurrent on one social networking website. In research about the use of this site as a teaching tool, Blattner/Fiori (2009: 24) point out that participants on the social networking website Facebook use more colloquial language in their speech acts and the tool "exposes learners to language varieties [...] that language departments and textbooks cannot match".

The use of Facebook in the university is more and more important: while emails are the most popular online genre for academics and administration, students now prefer to use social networking websites to communicate with other students; they are Internet "natives" who make competent daily use of these services (cf. Kuteeva 2011). Between $80 \%$ to $90 \%$ of the students on American campuses had Facebook accounts in 2006 (cf. Baron 2008). Hargittai/Hsieh (2011) point out that Facebook was the most popular social networking site in their survey carried out at the University of Illinois, Chicago, during 2006-2007, where 79\% of the students interviewed used it. Recently, Facebook has undergone a spectacular increase in users. Facebook itself estimates that more than 800 million people are active users in January 2012 and its use is increasing all over the world (Facebook Inc. 2012). The current relevance of Facebook has raised some voices of a possible competition between networking tools and, for example, email, however, as Cho (2010: 1) indicates, "evidence is inconclusive as to whether social networking services compete or facilitate email usage".

In this context, in order to fulfil the objectives of this research, a corpus of comments sent to Facebook websites of universities has been gathered over the last 2 years. As will be detailed 
below, the study analyses the opening and closing formulae used in this genre, available by this fairly recent application, in order to observe the degree of formality and informality the English language presents in a specific online environment. The distinction between native and non-native speakers of English is also a parameter of academic interest.

The research presented in this article forms part of what could be called the forth step in the research of computer-mediated communication (CMC), which deals with the study of electronic discourse in languages other than English, in non-anglophone fora or in nonEnglish-dominant countries, studies of special relevance according to Murray (2000). The study of the linguistics of Facebook is especially interesting due to its novelty, widespread use and the importance it is gaining in everyday life.

In the specific field of English for Academic Purposes, little attention has been devoted to the impact of the new genres developed by the Internet. The need to examine the changes that the new online genres imply for academic literacy practices is posed by Hyland/Hamp-Lyons (2002). More recently, Kuteeva (2011) has enhanced the study of the new online tools offered by Web 2.0 in more specific contexts, in light of the paucity of scholarly research realised up to date.

\section{$2 \quad$ Materials and Methods}

\subsection{Corpus}

The corpus of the study has been collected by the author during 2009 and 2010. It comprises 300 comments posted to the official Facebook sites of universities in Europe and The United States of America such as the University of Southern Denmark, The University of Edinburgh, The University of Manchester, The University of Oxford, The University of Warwick, Florida State University, Ohio State University, The University of Harvard, The University of Texas, and The University of Washington. All the texts studied have been written and posted on the official sites of the universities mentioned. The reason why these sites have been chosen is, firstly, because they are freely accessed sites open to the whole online community, that is, no member registration is needed to access the site; secondly, the language of communication on these sites is mostly English.

Some considerations about free access and privacy matters should be nuanced. Although the access of these sites is free, no authentic private information is published in the examples provided in this study. Private personal information on the comments has been modified, keeping similarities with the original as a proof of the authenticity of the written word, in accordance with the publication of early collections of letters (cf. Gurkin 1986). Authenticity has been a controversial issue since Medieval England as a criterion of source of authority in writing since the authority of a text depended not only on intrinsic worth but also on authenticity; the criterion demanded that the author be identifiable (cf. Baron 2000). In the last decade, the issue has gained importance in some areas such as sociolinguistics and anthropological studies (see, for example, Coupland 2003). As for computer-mediated communication, in this research it is necessary to focus on Baron's (2000) proposals when she points out that in online writing the traditional boundary between author and audience merges and "the notions of authority, responsibility, and ownership tend to crumble" (Baron 2000: 93). On Facebook, the platform allows users to decide what information about themselves they want to share with others; it is not to change identities but to present the best part of the user to the others (cf. Baron 2008). In this research, the presentation of self is not questioned or analysed, this could be a research topic in another study ${ }^{1}$. Thus, the information published by participants on their profiles concerning place of birth, place of living, and languages

\footnotetext{
${ }^{1}$ See Marwick (2005) for a study on authenticity and social networking.
} 
The linguistics of social networking: A study of writing conventions on Facebook

known, has been regarded as an authentic source of information to distinguish between native speakers of English and non-native. In CMC the distinction between native and non-native contexts is a parameter of importance for authors like Lan (2000), Li (2000) and Ancarno (2005), among others. The difference between native and non-native speakers of English always refers to the author of the written comment. The number of native and non-native comments analysed is equal, 150 in each category, following the suggestions of Rowe (2008). Lastly, as for the number of comments chosen, 300 posts was the work load the author could handle manually, since no software aided analysis of language could be used for this research.

\subsection{Methodological considerations}

\subsubsection{Methodological framework}

The drift towards orality in the English language use posited by eminent scholars such as Leech (1966), Biber and Finegan (1989), and Fairclough (1992) has also been of interest in computer-mediated communication (e.g. Baron 2000). Some parameters have been used to measure the degree of orality and informality in the new electronic genres, like the number of words per sentence, the use of paralinguistic cues, informal language, spelling mistakes and courtesy formulae (e. g. Pérez-Sabater et al. 2008b).

Following the studies on email by Gains (1999), Baron (2000), Waldvogel (2007), and BouFranch (2011), this research will examine the presence of the formulae of etiquette and protocol used for salutation, opening, pre-closing and closing in comments published on the social networking site Facebook. The findings will be compared with the results obtained in this parameter in other studies of computer mediated communication discourse already published on other CMC genres widely used in the university such as email and online forums.

Openings and closings, "the most salient structural features of an email" (Pérez-Sabater et al.: 2008a), are norms developed to structure and regulate conversations (cf. Murray 2000). Baron (2000) points out that although salutations and farewells tend to be sparse in emails as the name of the sender and addressee are known, conventions have evolved to open and close messages. Danet (2002) underlines the redundancy of including these salutations and closings as they appear at the top of the email. Other scholars also consider these elements as optional in emails, and therefore valuable for empirical research (cf. Bou-Franch 2011). On Facebook, in some cases the inclusion of greetings and farewells may also be redundant and, therefore, of research value, in some other situations, these strategies may be necessary to work out the current message's propositional meaning.

\subsubsection{Method of study}

To assess the formality or informality of the messages, the proposals of Pearce (2005), Duthler (2006) and the author's previous research (Pérez-Sabater et al. 2008a) are followed. Phatic communication in the form of greetings and farewell formulae have been studied according to the criteria established after an initial examination of the corpus, where the usual range of formulae from traditional letter writing is employed in some cases, while, in others, there is no use of these courtesy formulae. In this quantitative study, the corpus has been analysed following a scale ranging from "very formal" greetings and farewells to "very informal", using the criteria shown in Table 1. In this study, we associate the use of conversational traits in written texts to informality, while formality is related to nonconversational and impersonal registers (cf. Biber et al. 2002).

Thus, greetings beginning with $\mathrm{Dear} \mathrm{Mr} / \mathrm{Dr}+$ second name are considered very formal, Dear + first name formal, Hello + name informal and $\mathrm{Hi}$, Hey or a name very informal. Similarly, 
sign-offs like Yours sincerely are rated as very formal, Regards or Best wishes informal and Cheers, Bye or Kisses very informal.

\begin{tabular}{cc}
\hline Scale & Punctuation \\
\hline Very formal, separate from message body & 1.0 \\
Very formal non-separate & 0.9 \\
Formal separate & 0.8 \\
Formal non-separate & 0.7 \\
Informal separate & 0.4 \\
Informal non-separate & 0.3 \\
Very informal separate & 0.2 \\
Very informal non-separate & 0.1 \\
No greeting or farewell & 0 \\
\hline
\end{tabular}

Table 1: Assignation of formality degree

Secondly, the number of steps involved in the farewell is counted, that is, if there is a one-step closing or a two-step closing with a pre-closing of the type I look forward to hearing from you. No pre-closing scores 0 , one step closing scores 1 and 2 is assigned to two steps.

Finally, it is worth mentioning that two judges have been in charge of the coding process, as indicated by Duthler (2006). The results have been summed and averaged.

\subsection{Purpose of the study}

The comments posted on Facebook are characterised as asynchronous, that is, the mode of communication where the author and the reader are online at different times (Yus 2011). In contrast to synchronous communication, asynchronicity allows selective message construction (cf. Duthler 2006), authors are able to plan, review and control their texts more than in synchronous media like chats. Consequently, asynchronous online communication would allow a more formal style. Following this premise, the challenge of the study will be twofold:

- To examine online writings in one specific setting, i. e. the university, to see how a recent electronic genre, without imposing guidelines on participants, behaves in the use of openings and closings. The study of greetings and salutations is the parameter chosen to determine whether this tool of networking applications is already a conventionalized CMC genre despite its newness.

- To observe whether the writer's first language impinges upon the register and style of the comment, in other words, whether a different degree of formality/informality is followed by native and non-native speakers in this specific genre of electronic communication.

The results are shown in the light of outstanding previous research.

\section{Results/Discussion}

\subsection{Results}

Due to the informality of the electronic medium, many academics have pointed out the optionality of opening and closing formulae in online communication and their frequent absence, especially in emails (cf. Baron 1998; Yus 2001).

Table 2 shows the results obtained as for the level of formality in openings and closings. 


\begin{tabular}{llll}
\hline Groups & Openings & Closings & Sections \\
\hline Comments on Facebook native & 0,03 & 0,03 & 0,02 \\
Comments on Facebook non-native & 0,12 & 0,11 & 0,10 \\
\hline
\end{tabular}

Table 2: Results: level of formality in openings and closings

\subsubsection{Openings}

The results of this research show that in the comments of native speakers on Facebook, participants use either a very informal greeting element or no greeting formulae, the absence of greetings is a frequent strategy in $20 \%$ of the cases studied. Similarly, in the research of business and academic emails carried out by Gains (1999), most of the business emails didn't use a greeting formula, while the academic used informal greetings; Li's (2000) data present very informal greetings and Chiluwa's (2010) business emails show very informal introductions, as well. Thus, the informal results obtained in this research are the ones that would be expected in a priori informal CMC genre, as some previous studies on informal CMC genres such as online fora or chats conclude (e.g. Montero-Fleta et al. 2009; Yus 2001). On the other hand, the data shed light on some interesting issues that may need to be commented on.

Firstly, in the comments of native speakers it is important the extensive use of addressivity: $20 \%$ of the comments on Facebook analysed start their messages with the name or nickname of the intended addressee as in Example 1.

Example 1. Native speakers.

Darryl...buildings such as Thompson Library are possible because of generous donors...not tuition fees. Go Bucks!

The writer of this post needs to address a specific participant in the chained discussion arisen about the picture of the new library just uploaded on the Facebook site of The Ohio State University. As Werry (1996) comments, addressivity is a tool for topical cohesion. Unlike email where the email server provides the name of the addressee automatically, in Example 1, a name is necessary to clarify in order to whom the message is addressed, a strategy frequently found in synchronous CMC, such as chats (cf. Montero-Fleta et al. 2009) since comments are frequently posted as threads of conversation on a topic. In these cases, the "reference to the previous message is necessary to work out the current message's propositional meaning [without counting] instances of interpersonal meaning" (Lyons 1995: 44-45). Another important characteristic of adressivity is that it is a strategy of mitigation, as it reduces increased mental effort when trying to follow the threads in online conversation (Yus 2011). Besides, the need of an addressee reinforces the dialogic nature of CMC as messages are connected to previous ones and are related to future writings.

Secondly, another $20 \%$ of the comments posted by native speakers begin with exclamations of the type good day to all!, fantastic news!!! or exclamation words followed by one or some exclamation marks such as Wow!!. These initializations that include the reiterative use of exclamations, a characteristic of chat rooms (cf. Yus 2011), may show the playful and informal character of these comments, in spite of the formality of the setting where they are posted.

On the other hand, the findings point out that non-native speakers are a little more formal, as Examples 2 and 3 show. 
Example 2. Non-native speaker.

Dear Warwick,

Could you please provide me with a link that leads me to the webpage where it clearly outlines the "Refund Policy" of the tuition and accommodation fees?

Example 3. Non-native speakers.

Hi..

I Want to apply for a masters programme with good job placements. If there is still time left to apply for a course, can you please inform me of the same as well as the procedure!

The greeting in Example 2 addressed to the University of Warwick is formal and separated as for the use of Dear, a more frequent opening in professional or formal email writing than in informal CMC genres (cf. Pérez-Sabater et al. 2008a). Nevertheless, the name of the addressee being Warwick instead of a name reduces the initially formal character of the opening.

Similarly, this mixture of formal and informal styles is shown in Example 3, posted on the Facebook of the University of Southern Denmark, where, although the writer uses a very informal greeting with a repetition of punctuation, the structure is very formal with a separation between the opening and the message body, a formality which has been rarely observed in the comments written by native speakers studied. The perceived formality of nonnative writing may be due to the fact that non-native speakers prefer to use the discursive strategies of traditional letter writing so as to demonstrate their proficient use of the English language at least in a formal setting such as the university, an idea posited by Lan (2000). Conventional writing formulae are profusely taught in EFL textbooks; consequently, conventions of use are deeply rooted in non-native participants that adhere more frequently to these norms. Furthermore, non-natives may be insecure linguistically and associate formality to language correctness. Additional studies of this corpus will be needed to see if they also follow conventional letter writing norms because of transference from their own culture, as suggested by Rowe (2008).

\subsubsection{Closings}

The findings show that most comments incorporate a farewell formula which consists of a request or an expression of thanks with some emoticon or an exclamation, as a larger variety of sentiments can be found in leave taking formulae (cf. Cho 2010). The most popular closing formula in both groups is an informal expression of thanks with one or several exclamation marks, $20 \%$ of the messages of both groups end in a thank you formula, also the most popular closing in the examples analysed by Rowe (2008).

Example 4. Native speaker.

If you are attending or participating in the Arnold Classic and are willing to be interviewed for a story in my 421 class, please message me. Thank you!

Another salient finding is that in the comments of native speakers in American universities we often find a closing formula of the type Go Bucks!, Bucks being the short name for the sport teams of the Ohio State University (see Example 1), or Hook'em Horns, the slogan and hand signal of the University of Texas often used as a greeting or closing even in written 
The linguistics of social networking: A study of writing conventions on Facebook

documents. ${ }^{2}$ Together with colours, mascots and songs, slogans are the distinctive elements of a particular institution in American universities (cf. Toma 2003). These slogans serve to display the culture of the university in tangible and unique forms. Relatedly, moreover, their use in the comments reinforces the sense of community in social networking, it helps participants to create common ground, an important communicative purpose of online interaction (cf. Yus 2011). Slogans are privative of a specific community and only shared by members of a prestigious social group formed by students or former alumni of a university. The frequent use of these slogans suggests that a study of culturally dependent online interaction could be a follow up task with an exclusive and thorough analysis on the use of social networking in American Universities and in some British universities that share these cultural forms such as the University of Oxford or Cambridge, although no use of slogans as closings has been found in the British universities studied.

As for stylistic consistency between openings and closings, contrarily to the studies of Gains (1999) or Chiluwa (2010) on email, where sign-offs are more formal than greetings, in this corpus of comments on Facebook the correlation between the formality of openings and closings is clear in most cases. Most participants on Facebook show consistent levels of formality. However, some exceptions where writers do not observe a clear pattern of formality are worth mentioning. Example 4, written by a non-native speaker of English on the site of the University of Warwick, shows no opening but a very formal closing structure with two sections.

Example 5. Commentary on Facebook non-native speaker.

I really hope to continue my engineering master degree studies at this campus.

I had time to attend british council jakarta time the other day was held at the Ritz Carlton Hotel and are excited to continue my study at this campus

hopefully my future goals can be achieved by continuing the study at this campus amen

best regards

Mupriyadi Kamzah

from Indonesia

$\wedge$

On the other hand, this formal closing structure and the use of best regards doesn't correlate with informal features such as the absence of capital letters, punctuation, spelling mistakes and an emoticon, a combination of formal and informal registers observed in other CMC genres such as fora (cf. Montero-Fleta et al. 2009).

A rather different situation is found in the examples from native writers on Facebook, who seem to write more consistently and avoid the use of any formality in their comments. This may imply that for native speakers of English, comments on Facebook is an informal genre already conventionalized, regardless of its setting.

\subsection{Discussion}

The findings show that even within a single form of CMC there can be important differences. In the comments posted on the Facebook sites of these organisations, there is a clear diversity of use. On the one hand, we can observe that the comments on some universities' sites exhibit many features of a synchronous CMC genre, i. e., a chat where participants give their opinion on a topic or on a picture, in a very informal style without any type of introduction, and very 
soon after the topic is uploaded to the page (see, for example, the Facebook website of The Ohio State University). In many cases, these messages are semantically dependent on previous comments and are also frequently addressed to one of the participants of the "thread" with the name of the intended addressee, an important feature of synchronous CMC such as chats (cf. Montero-Fleta et al. 2009). Conversely, on other websites, such as the one of the Library of the University of Warwick, or the University of Southern Denmark, the comments sent to their site are highly formal with greetings and closings in most comments. In this context, when participants formulate a question, they are usually answered by the personnel of the university. These social networking websites seem to function as very formal forums, where the personnel of the university work as the webmasters controlling the style of this networking service. This is a challenge for universities as it requires daily maintenance and interaction with students but it may benefit the institution as future students may judge the college according to their experience on the university's social media accounts.

Deeply rooted in the sociolinguistic conventions of speech acts (cf. Strawson 1964), convention of use is a recurrent topic in the linguistics of computer-mediated communication. As suggested for early computer communication (cf. Ferrara et al. 1991), the use of Facebook is still in the process of becoming conventionalised; the stylistic variation perceived may be due to the novelty of the tool, to the fact that Facebook is a new communication tool and needs time to evolve and establish itself. In fact, the primary use of Facebook as a virtual place to keep in touch after graduating is no longer the only use. In the universities studied, Facebook also functions as a notice board in the university or the main page of the university website, with warnings about a snow storm, deadlines, or prizes awarded to the members of the university.

Finally, looking at the distinction between native and non-native speakers of English, it can be concluded that the results imply that non-native speakers use a more formal style than native writers, in the line of the research by Ancano (2005) on academic emails, Pérez-Sabater et al (2008a) on online fora or Rowe (2008) on web-based bulletin boards. In the corpus analysed, the differences in the level of stylistic formality observed between native and non-native authors may lend weight to the hypothesis that "it is not technology which determines the form and content of CMC but the set of cultural/literacy practices which the users bring to the medium" (Yates 2000: 241). As mentioned above, the association of linguistic formality to linguistic correctness could be one reason for a more formal linguistic behaviour of online writing (cf. Lan 2000). Further studies of participants' interaction in native and non-native environments would be needed to determine other reasons for this behaviour such a cultural transfer, an idea put forward by Rowe (2008). This research would imply the dedication of several specialists in different languages and the study of diverse online genres. Relatedly, the different levels of formality and informality appreciated may need further research with the study of other parameters.

\section{Conclusion}

From the result of this research it can be posited that the tendency towards informality, a long tradition in $\mathrm{CMC}$, is not unanimous as some Facebook comments in the university follow traditional letter writing conventions. On the other hand, the main problem with online genres according to Yus (2011) is the fact that the discursive traits of a genre should be conventionalised so that users can identify a genre at first sight and save time and effort of processing. The Facebook website doesn't bring about such a problem as the new social networking websites are easily identifiable and conventionalised, since they are privately owned by a company that creates, controls and modifies them. However, their use is not conventionalised enough: the Facebook comments studied exhibit stylistic variations in form and substance, which may have their origin in the fact that these variations in a new medium 
reflect the ambiguity among individuals about its adequacy (cf. Yates/Orlikowski 1992). In this research, it has been posited that this new compendium of online services has not been able to "produce consistently and efficiently and to relate its production to the expectations of its customers" (McQuail 1987: 200).

The innovative force of Facebook has made it a place for everything: its primary aim to be a platform to keep in touch with friends has grown to incorporate other uses, for instance, in the corpus of this research, it works as the administration office within the university. Facebook is evolving rapidly and we may need some time to see if this social networking website will gain a permanent status, at least in a specific context like a university. Further studies on the linguistics of social networking websites are needed to address the issues this article has given rise to. A special regard to Twitter will also be of scholarly interest in follow up research.

\section{References}

Ancarno, Clyde (2005): "The Style of Academic E-mails and Conventional Letters: Contrastive Analysis of Four Conversational Routines". Ibérica 9: 103-122.

Bakhtin, Mikhail (1986): Speech Genres and Other Late Essays. Austin, Tx: University of Texas Press.

Baron, Naomi S. (1998): "Letters by Phone or Speech by Other Means: The Linguistics of Email". Language and Communication 18: 133-170.

Baron, Naomi S. (2000): Alphabet to Email. London: Routledge.

Baron, Naomi S. (2008): Always on: Language in an Online and Mobile World. New York: Oxford University Press.

Biber, Douglas/Finegan, Edward (1989): "Drift and the Evolution of English style: A History of three Genres". Language 65/3: 487-517.

Biber, Douglas/Conrad, Susan/Leech, Geoffrey (2002): Student Grammar of Spoken and Written English. Harlow: Longman.

Blattner, Geraldine/Fiori, Melissa (2009): "Facebook in the Language Classroom: Promises and Possibilities". International Journal of Instructional Technology and Distance Learning 6/1: 17-28.

Bou-Franch, Patricia (2011): "Openings and Closings in Spanish Email Conversations". Journal of Pragmatics 43/6: 1786-1800.

Boyd, Danah M./Ellison, Nicole B. (2008): "Social Networking Sites: Definition, History, and Scholarship". Journal of Computer-Mediated Communication 13 (1), article 11. http://jcmc.indiana.edu/vol13/issue1/boyd.ellison.html, accessed November 27, 2012.

Chiluwa, Innocent (2010): "The Pragmatics of Hoax Email Business Proposals". Linguistik Online 43/3: 3-17.

Cho, Thomas (2010): "Linguistic Features of Electronic Mail in the Workplace: A Comparison with Memoranda". Language and the Internet 7: 1-28.

Coupland, Nikolas (2003): "Sociolinguistic Authenticities". Journal of Sociolinguistics 7/3: 417-431.

Danet, Brenda (2002): "The Language of Email". European Union Summer School, University of Rome. Available at http://www.europhd.it/html/_onda02/04/ss8/pdf_files/lectures/Danet_email.pdf , accessed May 5, 2011.

Duthler, Kirk W. (2006): "The Politeness of Requests Made via Email and Voicemail: Support for the Hyperpersonal Model". Journal of Computer-Mediated Communication $11 / 2$.

Ellison, Nicole/Steinfield, Charles/Lampe, Cliff (2007): "The Benefits of Facebook 'Friends': Exploring the Relationship between College Students' Use of Online Social Networks and Social Capital". Journal of Computer-mediated Communication 12 (3), article 1. http://jcmc.indiana.edu/vol12/issue4/ellison.htm, accessed November 27, 2012. 
Emmerson, Paul (2004): Email English. Oxford: Macmillan.

Facebook Inc. (2012): www.facebook.com, accessed January 11, 2012.

Fairclough, Norman (1992): Discourse and Social Change. Oxford: Polity Press.

Ferrara, Kathleen/Brunner, Hans/Whittemore, Greg (1991): "Interactive Written Discourse as an Emergent Register". Written Communication 8/1: 8-34.

Gains, Jonathan (1999): "Electronic Mail-a New Style of Communication or just a New Medium?: An Investigation into the Text Features of E-mail". English for Specific Purposes 18/1: 81-101.

Grubbs, Jim (2004): "E-mail and Instant Messaging". In: Bidgoli, Hossein (ed.) (2004): The Internet Encyclopedia. Hoboken, New Jersey, Wiley: 660-670.

Gurkin Altman, Janet (1989): "The Letter Book as a Literary Institution 1539-1789: Toward a Cultural History of Published Correspondences in France". Yale French Studies 71: 17-62.

Hargittai, Eszter/Hsieh, Yu-Li P. (2011): "From Dabblers to Omnivores". In: Papacharissi, Zizi (ed.) (2011): A Networked self: Identity, Community, and Culture in Social Network Sites. New York/London, Routledge: 146-168.

Herring, Susan (2001): "Computer-Mediated Discourse". In: Schiffrin, Deborah / Tannen, Deborah/Hamilton, Heidi (eds.) (2001): Handbook of Discourse Analysis. Oxford, Blackwell: 612-634.

Hyland, Ken/Hamp-Lyons, Liz (2002): "EAP: Issues and Directions". Journal of English for Academic Purposes 1/1: 1-12.

Kuteeva, Maria (2011): "Wikis and Academic Writing: Changing the Writer-Reader Relationship". English for Specific Purposes 30/1: 44-57.

Lan, Li (2000): "Email: A Challenge to Standard English?" English Today 16/4: 23-29.

Leech, Geoffrey (1966): English in Advertising. London: Longmans.

Li, Yongyan (2000): "Surfing E-mails". English Today 64/16: 30-40.

Lyons, John (1995): Linguistic Semantics. Cambridge: Cambridge University Press.

Marwick, Alice (2005): "'I'm a lot more interesting than a Friendster profile': Identity presentation, authenticity and power in social networking services". Paper presented at The Conference of the Association of Internet Researchers 6, Chicago (USA), October 2005.

Maynor, Natalie (1994): "The Language of Electronic Mail: Written Speech?" In: Little, Greta D./Montgomery, Michael (eds.) (1994): Centennial Usage Studies. Tuscaloosa, Al.: Alabama U.P: 48-54.

McQual, Denis (1987): Mass Communication Theory: An Introduction. Thousand Oaks, California: Sage.

Montero-Fleta, Begoña/Montesinos López, Anna/ Pérez-Sabater, Carmen/Turney, Edmund (2009): "Computer mediated communication and informalization of discourse: The influence of culture and subject matter". Journal of Pragmatics 41/4: 770-779.

Murray, Denise (2000): "Protean Communication: The Language of Computer-Mediated Communication". Tesol Quarterly 34/3: 397-421.

Pearce, Michael (2005): "Informalization in UK Party Election Broadcasts 1966-1997". Language and Literature 14: 65-90.

Pérez-Sabater, Carmen (2011): "Cartas por Internet: Las Implicaciones Lingüísticas y Estilísticas de los Mensajes de Correo Electrónico y los Comentarios del Sitio de Redes Sociales Facebook". RESLA 24: 111-130.

Pérez-Sabater, Carmen/Turney, Edmund/Montero-Fleta, Begoña (2008a): "Orality and Literacy, Formality and Informality in Email Communication". Ibérica 15: 71-88.

Pérez-Sabater, Carmen/Turney, Edmund/Montero-Fleta, Begoña (2008b): "A Spoken Genre Gets Written: Online Football Commentaries in English, French and Spanish". Written Communication 25/2: 235-261. 
Rowe, Charley (2008): "Hyper-formality and Ultra-casualness: Native and Non-native English Style on the Ask-A-Linguist Web-based Bulletin Board". Bulletin Suisse de Linguistique Appliquée 87: 27-54.

Strawson, Peter Frederick (1964): "Intention and Convention in Speech Acts". Philosophical Review 73: 439-460.

Toma, J. Douglas (2003): Football U.: Spectator Sports in the Life of the American University. Michigan: The University of Michigan Press.

Waldvogel, Joan (2007): "Greetings and Closings in Workplace Email". Journal of Computer-Mediated Communication 12/2: article 6.

Werry, Cristopher (1996): "Linguistic and Interactional Features of Internet Relay Chat". In: Herring, Susan C. (ed.) (1996): Computer-Mediated Communication: Linguistic, Social and Cross-Cultural Perspectives. Amsterdam/Philadelphia, John Benjamins: 47-61.

Yates, Joanne/Orlikowski, Wanda J. (1992): "Genres of Organizational Communication: A Structurational Approach to Studying Communication and Media". Academy of Management Review 17/2: 299-326.

Yates, Simeon J. (2000): "Computer-Mediated Communication, The Future of the Letter?" In: Barton, David/Hall, Nigel (eds.) (2000): Letter Writing as a Social Practice. Amsterdam/Philadelphia, John Benjamins: 233-252.

Yus, Francisco (2001): Ciberpragmática. Barcelona: Ariel.

Yus, Francisco (2011): Cyberpragmatics: Internet-Mediated Communication in Context. Amsterdam/Philadelphia: John Benjamins.

Zimmerman, Eric/Bar-Ilan, Judit (2009): "PIM @ Academia: How E-mail is used by Scholars?" Online Information Review 33/1: 22-44. 